\title{
Multiblock Polyurethanes Based on Biodegr- adable Amphiphilic Poly(E-caprolactone)/ Poly(ethylene glycol) Segments as Candidates for Tissue Engineering Applications
}

Irene Bartolozzi, Stefania Cometa, Cesare Errico, Federica Chiellini, Emo Chiellini*

Laboratory of Bioactive Polymeric Materials for Biomedical and Environmental Applications (BIOlab) UdR-INSTM-Department of Chemistry and Industrial Chemistry, University of Pisa-Via Vecchia Livornese 1291, 56010, S. Piero a Grado (Pisa), Italy

* Corresponding author: emochie@dcci.unipi.it (Emo Chiellini) Tel.: 0039-050-2210301; Fax: 0039-050-2210332

\begin{abstract}
Biodegradable amphiphilic multiblock poly(ether-ester-urethane)s were prepared by one-step bulk polycondensation of PEG and PCL macrodiols and HMDI with good yields and high molecular weights. The copolymers were characterized by ${ }^{1} \mathrm{H}-\mathrm{NMR}$, FT-IR, SEC, TGA and DSC analysis. Different ratios of PEG/PCL, PEG macromonomer length and copolymer molecular weights allowed for tuning their hydrophilicity. Thanks to their tunable characteristics, the prepared multiblock copolymers can be exploited in the fabrication of biodegradable scaffolds for tissue engineering by means of the electrospinning technique.
\end{abstract}

Keywords: Polycondensation, Tissue engineering, Thermal properties, Block copolymers, Electrospinning.

Citation: Irene Bartolozzi et al, Multiblock Polyurethanes Based on Biodegradable Amphiphilic Poly( $\varepsilon$-caprolactone)/poly(ethylene glycol) Segments as Candidates for Tissue Engineering Applications, Nano Biomed. Eng. 2011, 3(2), 86-94. DOI: 10.5101/nbe.v3i2.p86-94.

\section{Introduction}

Biodegradable poly(ether-ester-urethane)s (PEEUs) have drawn attention in the biomedical field, where they have been used as bioabsorbable sutures [1,2], drug delivery systems [3, 4], biodegradable vascular grafts [5] and, in general, in the fabrication of scaffolds for Tissue Engineering (TE) [6-8].

In fact, suitable mechanical properties and biodegradation rates of scaffolds for TE applications can be tuned by tailoring the chemical composition and the macromolecular architecture. In particular, the presence of hard and soft segments, their different ratios, as well as the polymer molecular weight, affect the final properties of PEEUs, making them suitable for various applications.

Polyethylene glycol (PEG) and poly( $\varepsilon$-caprolactone) (PCL) are very extensively used soft segments for their well proofed biocompatibility, and they are combined in copolymers to afford useful features. PCL is extensively used as surgical material. Its hydro-biodegradation yields 6-hydroxyhexanoic acid, a natural occurring metabolite which ultimately can be metabolized to $\mathrm{CO}_{2}$ and water.
It is a semicrystalline polymer with $\mathrm{T}_{\mathrm{m}}$ around $60{ }^{\circ} \mathrm{C}$ and although hydro-biodegradable, its crystallinity and hydrophobicity result in long degradation times [9]. Low molecular weight PEG is a biocompatible hydrophilic and highly flexible polymer, not biodegradable but able to be eliminated from the body by the renal system (bioeliminable) [10]. It is often used in copolymers with PCL to increase the hydrophilicity and decrease the crystallinity of the polyester segment and thus to tune the mechanical properties and the biodegradation rates [11].

PEEUs containing PEG and PCL have been prepared with different methods, in most cases by using a two step prepolymer technique. Chain extension of PCLPEG-PCL triblock copolymers was carried out with different diisocyanates including, among the others, methylene-bis-(cyclohexyldiisocyanate) (MBCDI) [12] or hexamethylenediisocyanate (HMDI) $[6,13]$ to give alternating polyurethanes. Yeganeh et al. prepared elastomeric hydro-biodegradable PEG-PCL based polyurethanes for soft TE by chain extending epoxy- 
terminated polyurethanes with a multistep synthesis [14]. As for the one-step synthesis, Lee et al. obtained random multiblock copolymers by one-pot condensation polymerization of PEG and PCL diols with HMDI [15].

Polymeric materials based on PEEUs have often exhibited excellent elastomeric properties. These properties have been exploited to prepare nanofibrous three-dimensional scaffolds for vascular grafts applications, by an electrospinning process. This process provides complex architectures that have become extensively desired since they resemble that of the extracellular matrix (ECM) present in the living tissue.

In this work, segmented PEEUs - coded as PEGCL copolymers - obtained by coupling PCL and PEG segments, have been prepared. In previous works, the hydrophilicity and the degradation rate, as well as the influence of the surface composition of these PCL/PEGbased materials on cell adhesion have been assessed [16, 17].

Here we deepened the investigation on the synthesis and characterization of PEGCL copolymers, in view of their potential application as materials for TE. In particular, the synthesis of these random copolymers was optimised to afford a fast, reproducible, one-step and solvent-free method, and the structure-property relationships were also deeply investigated. Moreover, the attention was focused on the evaluation of the thermal properties of the proposed materials. The copolymers displayed phase segregation of the two components, in confirmation of our previous investigations [17]. Finally, a preliminary study on the suitability of these copolymers to be processed into nanofibers by electrospinning technology is reported.

\section{Experimental Section}

\section{Materials and Methods}

All reagents were purchased from Sigma Aldrich unless otherwise noted. Toluene (J.T. Baker) was refluxed over sodium and distilled before use. 1,6-Hexamethylendiisocyanate (HMDI) was distilled at reduced pressure $\left(65^{\circ} \mathrm{C} / 0.2 \mathrm{mbar}\right)$. PEG-diol (MW 2000 or 3400) and PCL-diol (MW 2000) were dried by azeotropic distillation with toluene and further dried under vacuum. Tin(2-ethyl-hexanoate) $\left(\mathrm{SnOct}_{2}\right)$ was used as received.

\section{Synthesis of poly(ether ester urethane)s (PEEUs)}

PEG- and PCL-diols in different ratios were thoroughfully dried by azeotropic distillation with toluene and then under vacuum. A stoichiometric amount of 1,6-hexamethylenediisocyanate was added to the melted mixture together with a few drops of $\mathrm{SnOct}_{2}$. The solution was stirred at $70{ }^{\circ} \mathrm{C}$. The copolymers were recovered after double precipitation in methanol and petroleum ether and dried until constant weight (yields 85-95\%). ${ }^{1} \mathrm{H}-\mathrm{NMR}$ $\left(\mathrm{CDCl}_{3}, 200 \mathrm{MHz}\right) \delta$ : 1.3-1.4 (2 H, $\left.\mathrm{CH}_{2}-\mathrm{CH}_{2}-\mathrm{CH}_{2}\right)$, 1.6- $1.7\left(6 \mathrm{H}, \mathrm{CH}_{2}-\mathrm{CH}_{2}-\mathrm{NH}, \mathrm{CH}_{2}-\mathrm{CH}_{2}-\mathrm{O}-\mathrm{C}=\mathrm{O}, \mathrm{CH}_{2}-\mathrm{CH}_{2}-\right.$ $\mathrm{C}=\mathrm{O}-\mathrm{O}), 2.3\left(2 \mathrm{H}, \mathrm{CH}_{2}-\mathrm{C}=\mathrm{O}-\mathrm{O}, \mathrm{PCL}\right), 3.1\left(4 \mathrm{H}, \mathrm{CH}_{2}-\right.$ $\left.\mathrm{CH}_{2}-\mathrm{NHC}=\mathrm{O}, \mathrm{HMDI}\right), 3.6\left(4 \mathrm{H}, \mathrm{CH}_{2}-\mathrm{CH}_{2}-\mathrm{O}, \mathrm{PEG}\right), 4.1$ (2 $\left.\mathrm{H}, \mathrm{CH}_{2}-\mathrm{CH}_{2}-\mathrm{O}-\mathrm{C}=\mathrm{O}, \mathrm{PCL}\right), 4.2\left(2 \mathrm{H}, \mathrm{O}-\mathrm{CH}_{2}-\mathrm{CH}_{2}-\mathrm{O}-\right.$ $\mathrm{C}=\mathrm{O}-\mathrm{NH}, \mathrm{PEG}) \mathrm{ppm}$.

FT-IR (cast film): 3445-3370 (NH), 2950 and 2865 ( $\mathrm{vCH}_{2}$ aliphatic), 1725 ( $\mathrm{v} \mathrm{C}=\mathrm{O}$ ester $), 1660(\mathrm{C}=\mathrm{O}$ amide $\mathrm{I})$, 1540 ( $\mathrm{C}=\mathrm{O}$ amide II), 1243 (vCOO ester), 1110 (vC-O-C, ether) $\mathrm{cm}^{-1}$.

\section{Characterizations}

FT-IR spectra were acquired on a Perkin-Elmer 1600 x FTIR spectrometer on polymer cast films. ${ }^{1} \mathrm{H}-\mathrm{NMR}$ spectra were acquired on a Varian Gemini 200 spectrometer in $\mathrm{CDCl}_{3}$.

Size exclusion chromatography (SEC) analyses were performed at a flow rate of $1.0 \mathrm{ml} \mathrm{min}^{-1}$ by using a Jasco PU-1580 HPLC liquid chromatograph connected to Jasco 830-RI and Perkin-Elmer LC-75 spectrophotometric $(\lambda=$ $260 \mathrm{~nm}$ ) detector, and equipped with two Mixed-D PLgel columns $(300 \times 7.5 \mathrm{~mm})$. Chloroform was used as the eluent and the calibration curve was prepared by using mono-dispersed polystyrene standards.

Differential scanning calorimetry (DSC) measurements were performed by using a Mettler TA 4000 instrument on samples of 10-15 mg, under nitrogen atmosphere, at a heating and a cooling rate of $10{ }^{\circ} \mathrm{C} \mathrm{min}^{-1}$.

Thermogravimetric analysis (TGA) measurements were carried out with a TAQ 500 MFC system equipped with thermogravimetric analyzer software in the temperature range from 30 to $600{ }^{\circ} \mathrm{C}$ at $10{ }^{\circ} \mathrm{C} \mathrm{min}^{-1}$ heating rate under nitrogen.

Wide Angle X-ray Diffraction (WAXD) patterns were acquired by using nickel-filtered $\mathrm{Cu}-\mathrm{K} \alpha$ radiation (Rigaku Denki Model RAD-C diffractometer). The X-ray diffractometer operated at $40 \mathrm{kV}$ and $180 \mathrm{~mA}$ in the $2 \theta$ scanning mode between 5 and 35 degrees.

\section{Electrospinning}

Preliminary experiments of electrospinning were performed on the PEGCL-I-25_2 copolymer. The electrospinning apparatus consisted of a $10 \mathrm{ml}$ syringe equipped with a 21-gauge blunt needle, a syringe pump (BSP- 99 M, Braintree Scientific Inc., Braintree, MA) and two high voltage power supplies of opposite polarity (Spellman High Voltage, UK). To obtain focused fiber collections, a screen-to screen electrode configuration was employed, composed of two parallel metallic screens at different electrical potentials, one functioning as a fiber collector and the other one as an auxiliary electrode. The fluid was fed at a given flow rate to the metallic needle jutting out of a hole in the middle of one plate and the fibers were collected onto the other plate.

A solution of PEGCL-I-25_2 in chloroform (10\% w/ v) was electrospun at $2 \mathrm{~mL}$ hour ${ }^{-1}$ flow rate with spinning voltage at 30 and $46 \mathrm{KVolt}$ and $30 \mathrm{~cm}$ distance needle to collector. 


\section{Morphological analysis}

The top surface of polymeric nanofibrous samples was investigated by means of scanning electron microscopy (SEM; Jeol LSM 5600LV, Japan).

\section{Results And Discussion}

\section{Synthesis and Characterization of PEGCL copolymers}

The biodegradable segmented PEEUs were synthesised by one-step random condensation polymerization, as shown in Scheme 1.
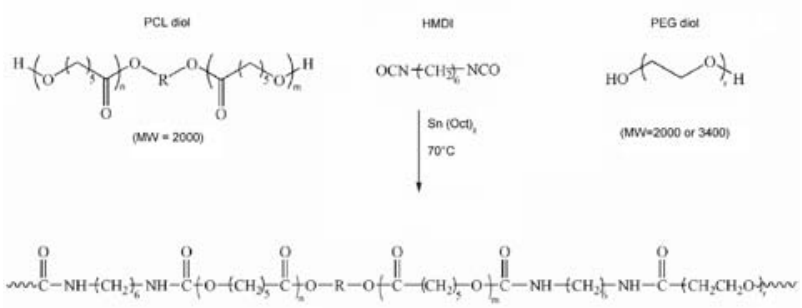

Scheme 1 Synthesis of PEEUs.

PEG macrodiols with molecular weight 2000 or 3400 and PCL macrodiols with molecular weight 2000 were used in different ratios (Table 1).

PEG- and PCL-diol oligomers were reacted in bulk together with stoichiometric amounts of HMDI as chain extender. The reaction was speeded up by adding SnOct $_{2}$ as catalyst and stopped when viscosity was too high to allow the stirring of the mixture. To remove the catalyst, the copolymer was recovered by double precipitation in methanol and petroleum ether with yields ranging between $85-95 \%$.

Table 1. Characterization of the PEGCL copolymers.

\begin{tabular}{|c|c|c|c|c|}
\hline Run a) & PEG & $\begin{array}{c}\text { PCL/ } \\
\text { PEG }\end{array}$ & Mn b) & Mw/Mn b) \\
\hline PCL-HMDI & $/$ & $1 / 0$ & 42000 & 1.7 \\
\hline PEGCL-I-50 & 2000 & $0.5 / 0.5$ & 72000 & 3.3 \\
\hline PEGCL-I-25_1 & 2000 & $0.75 / 0.25$ & 62000 & 2.6 \\
\hline PEGCL-I-25_2 & 2000 & $0.75 / 0.25$ & 331000 & 1.9 \\
\hline PEGCL-II-25 & 3400 & $0.75 / 0.25$ & 45000 & 1.9 \\
\hline
\end{tabular}

a) PCL MW = 2000; b) Evaluated by SEC.

FT-IR spectra exhibited the most significant peaks of the two components, qualitatively confirming the copresence of PEG and PCL. Fig. 1 shows the overlaid FTIR spectra of PCL-HMDI and PEGCL-I-25_1.

The absorption bands at 1110 and $1243 \mathrm{~cm}^{-1}$ (a and b) are attributed to the characteristic $\mathrm{C}-\mathrm{O}-\mathrm{C}$ stretching vibration of the repeated $\mathrm{O}-\mathrm{CH}_{2}-\mathrm{CH}_{2}$ - units of $\mathrm{PEG}$ backbone and $-\mathrm{C}(=\mathrm{O}) \mathrm{O}-$ stretching vibrations of $\mathrm{PCL}$ repeated units, respectively. The absorption band at $1540 \mathrm{~cm}^{-1}$ (c) $(\mathrm{N}-\mathrm{H}$ bending vibrations) confirms the formation of a urethane group in the copolymers. The

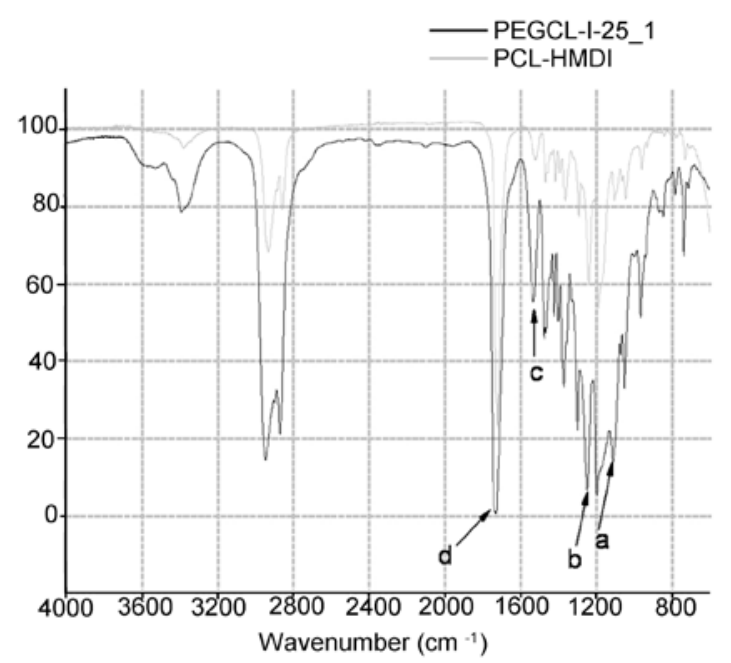

Fig. 1 FT-IR spectrum of PEGCL-I-25 and PCL-HMDI.

strong $\mathrm{C}=\mathrm{O}$ stretching band at $1725 \mathrm{~cm}^{-1}$ (d) is attributed to $-\mathrm{C}(=\mathrm{O}) \mathrm{O}-\mathrm{CH}_{2}$ - ester bonds typical of PCL moieties. No absorption is observed in the range of $2270-2285 \mathrm{~cm}^{-1}$ range, thus confirming that the NCO groups of HMDI have reacted completely.

${ }^{1} \mathrm{H}-\mathrm{NMR}$ spectra exhibited all the relevant peaks of the two components. The ratio of the PEG and PCL blocks was calculated from the relative intensities of the peak at $3.6 \mathrm{ppm}$ for the $\left(\mathrm{CH}_{2} \mathrm{CH}_{2} \mathrm{O}\right)$ of PEG and from the peak at $4.1 \mathrm{ppm}$ for the $\left(\mathrm{CH}_{2}-\mathrm{OC}=\mathrm{O}\right)$ of $\mathrm{PCL}$ and is in agreement with the ratio of the feed mixture.

SEC analysis did not show any low molecular weight peaks attributable to the starting macromonomers. However, as expected in a polycondensation process, fairly broad molecular weight distributions were observed, suggesting that low molecular weight components might still be present after the purification. It should be highlighted that the calibration curve with polystyrene does not allows for determining the real MW value, being the hydrodynamic volume of PS fairly different from that of the PCL/PEG polymers and therefore a different standard or a different technique should be employed. Nevertheless, this method is useful for a comparative evaluation among the set of the prepared polymers.

\section{Thermal properties}

The thermal behaviour of the PEGCL copolymers was investigated by differential scanning calorimetry (DSC) and the relevant data are reported in Tables 2 and 3.

In Fig. 2, the DSC traces relevant to the second heating cycle applied to the PEGCL copolymers were shown.

Samples were first heated to $150^{\circ} \mathrm{C}$ to erase the thermal history, then cooled to $-100^{\circ} \mathrm{C}$ and heated again to $120^{\circ} \mathrm{C}$. The scans were run at $10{ }^{\circ} \mathrm{C} \mathrm{min}^{-1}$ and glass transitions and melting events were evaluated in the second heating scans. Both PEG and PCL are semicrystalline polymers and therefore a similar behaviour is expected from their copolymers. The glass transition temperature $\left(\mathrm{T}_{\mathrm{g}}\right)$ was not detected for PEG2000 and PEG3400 oligomers. A large 
Table 2. DSC first cooling scan of the PEGCL copolymers and their macromonome

\begin{tabular}{|c|c|c|c|c|c|c|}
\hline Run & $\begin{array}{l}\text { Tc1 } \\
\left({ }^{\circ} \mathrm{C}\right)\end{array}$ & $\begin{array}{l}\Delta \mathrm{Hc1}^{-1} \\
\left(\mathrm{~J} \mathrm{~g}^{-1}\right)\end{array}$ & $\begin{array}{l}\text { Tc2 } \\
\left({ }^{\circ} \mathrm{C}\right)\end{array}$ & $\begin{array}{l}\Delta \mathbf{H c 2} \\
\left(\mathrm{J} \mathrm{g}^{-1}\right)\end{array}$ & $\begin{array}{l}\mathrm{Tg} \\
\left({ }^{\circ} \mathrm{C}\right)\end{array}$ & $\begin{array}{c}\Delta \mathbf{C p} \\
\left(J^{-1} g^{-1}\right)\end{array}$ \\
\hline PEG2000 & 30.7 & 178.8 & I & I & I & I \\
\hline PEG3400 & 34.4 & 177.6 & l & l & / & I \\
\hline PCL2000 & 26.7 & 81.5 & l & l & -69.7 & 0.14 \\
\hline PCL-HMDI & 13.6 & 53.3 & I & I & -58.4 & 0.16 \\
\hline PEGCL-I-50 & 8.7 & 31.9 & 0.2 & 31.1 & -57.1 & 0.36 \\
\hline PEGCL-I-25_1 & 15.1 & 44.2 & -30.7 & 4.0 & -59.8 & 0.28 \\
\hline PEGCL-I-25_2 & 1.6 & 36.1 & I & l & -61.4 & 0.51 \\
\hline PEGCL-II-25 & 10.4 & 32.9 & -8.2 & 14.6 & -57.9 & 0.23 \\
\hline
\end{tabular}

Table 3. DSC second heating scan of PEGCL copolymers and their macromonomers.

\begin{tabular}{|c|c|c|c|c|c|c|c|c|}
\hline Run & $\begin{array}{c}\mathbf{T g} \\
\left({ }^{\circ} \mathbf{C}\right)\end{array}$ & $\begin{array}{c}\Delta \mathbf{C p} \\
\left(\mathbf{J ~ g}^{-1} \mathbf{K}\right)\end{array}$ & $\begin{array}{c}\mathbf{T m 1} \\
\left({ }^{\circ} \mathbf{C}\right)\end{array}$ & $\begin{array}{c}\Delta \mathbf{H m 1} \\
\left(\mathbf{J ~ g}^{-1}\right)\end{array}$ & $\begin{array}{c}\mathbf{T m 2} \\
\left({ }^{\mathbf{O}} \mathbf{C}\right)\end{array}$ & $\begin{array}{c}\Delta \mathbf{H m 2} \\
\left(\mathbf{J ~ g}^{-1}\right)\end{array}$ & $\begin{array}{c}\mathbf{T c r y s t} \\
\left({ }^{\circ} \mathbf{C}\right)\end{array}$ & $\begin{array}{c}\Delta \mathbf{H c r y s t} \\
\left(\mathbf{J ~ g}^{-1}\right)\end{array}$ \\
\hline PEG2000 & $/$ & $/$ & 39.0 & 4.5 & 55.4 & 177.0 & $/$ & $/$ \\
\hline PEG3400 & $/$ & $/$ & 55.0 & 65.0 & 56.9 & 122.7 & $/$ & $/$ \\
\hline PCL2000 & -66.9 & 0.25 & 45.2 & 52.7 & 50.4 & 28.3 & $/$ & $/$ \\
\hline PCL-HMDI & -56.5 & 0.29 & $/$ & $/$ & 46.4 & 54.9 & $/$ & $/$ \\
\hline PEGCL-I-50 & -55.2 & 0.21 & 35.1 & 47.6 & 47.1 & 22.9 & $/$ & $/$ \\
\hline PEGCL-I-25_1 & -57.7 & 0.33 & 21.1 & 19.2 & 45.9 & 42.7 & -35.7 & 3.3 \\
\hline PEGCL-I-25_2 & -56.9 & 0.51 & $/$ & $/$ & 41.9 & 40.4 & -30.9 & 3.1 \\
\hline PEGCL-II-25 & -57.7 & 0.30 & 39.6 & 30.7 & 46.4 & 34.7 & $/$ & $/$ \\
\hline
\end{tabular}

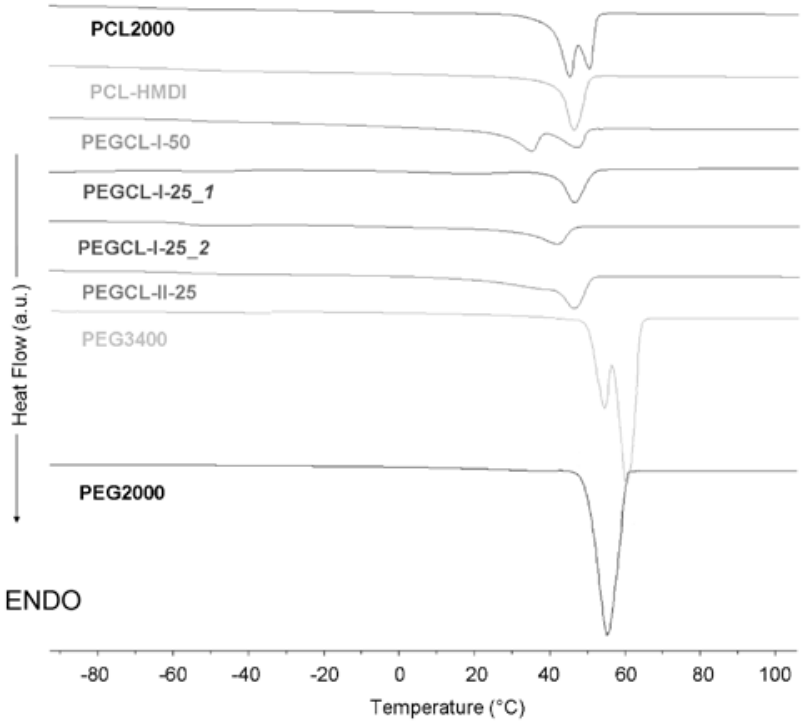

Fig. 2 DSC second heating scans of PEGCL copolymers and their precursors.

melting peak at $55.4{ }^{\circ} \mathrm{C}$ and a very small one at $39.0^{\circ} \mathrm{C}$ were observed for PEG2000; in the case of PEG3400, two adjacent melting peaks, falling at 55 and $57^{\circ} \mathrm{C}$, were detected. The two peaks present in the endotherm in the second heating curve correspond to the melting of PEG lamellae with different fold numbers [18]. PCL2000 exhibited a $\mathrm{T}_{\mathrm{g}}$ at $-66.9{ }^{\circ} \mathrm{C}$ and two melting peaks at $45.2^{\circ} \mathrm{C}$ and $50.4^{\circ} \mathrm{C}$.

For all the copolymers, a single glass transition was observed, which was attributed to the PCL component. Compared to the pristine PCL2000, the $\mathrm{T}_{\mathrm{g}}$ values were shifted of $10-12{ }^{\circ} \mathrm{C}$ to higher temperature, namely around $-55--57^{\circ} \mathrm{C}$, thus suggesting a stiffening of the structure due to the increase in molecular weight and to the strong interchain interactions established through $\mathrm{H}$-bonds between urethane groups and carbonyl or ether oxygen atoms. In addition, the presence of crystalline domains, which form physical crosslinking, might contribute to this stiffening.

In the first cooling scan, the PEG2000, PEG3400 and PCL2000 oligomers exhibit a single crystallization peak at $30.7,34.4$ and $26.7^{\circ} \mathrm{C}$, respectively. The examined copolymers exhibit two crystallization peaks: the first one around $8-15{ }^{\circ} \mathrm{C}$ is attributed to the PCL component, since also PCL-HMDI exhibits a single crystallization peak at $13.6^{\circ} \mathrm{C}$. The second peak appears at lower temperature and is attributed to the PEG component, whose 

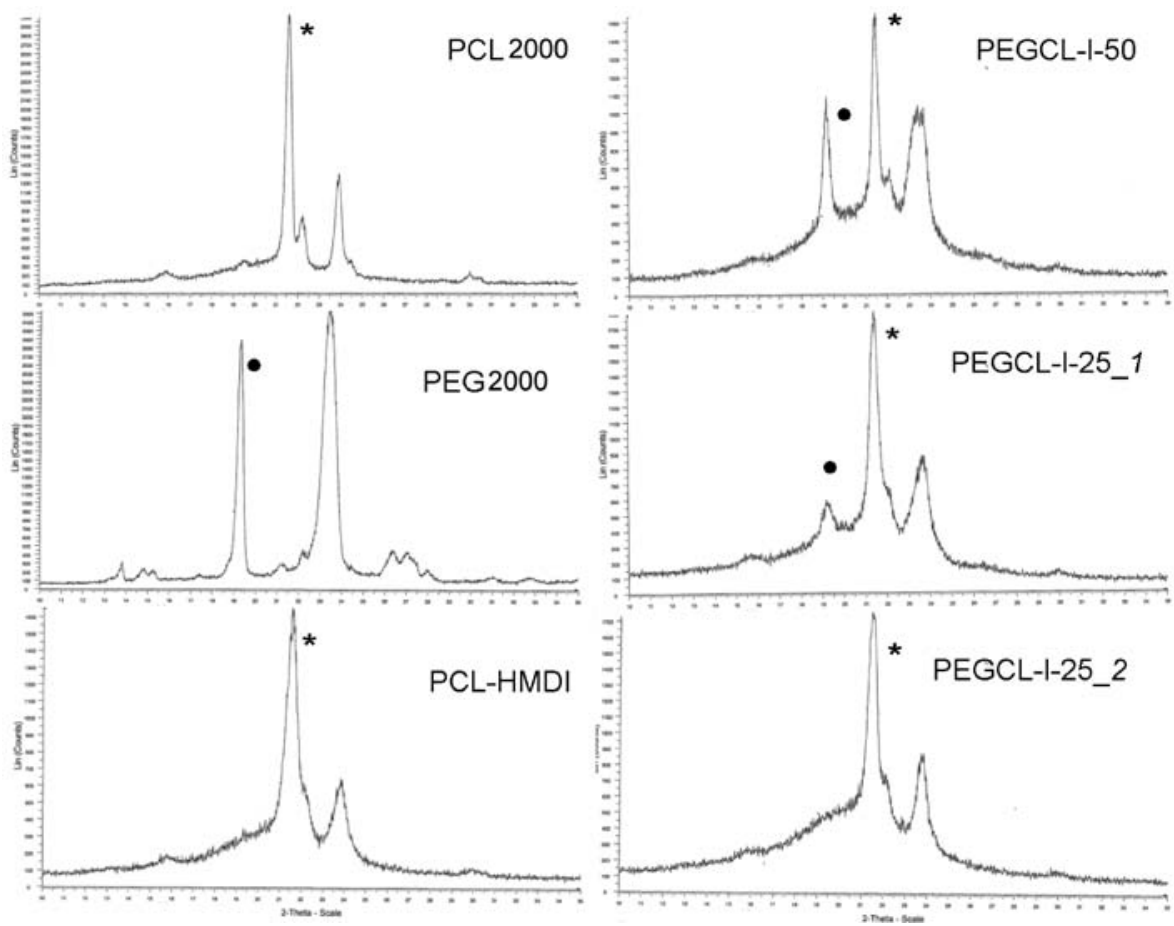

Fig. 3 WAXD patterns of PCL and PEG macrodiols, PCL-HMDI and PEGCL copolymers. The star and the solid dot indicate the diffraction peaks used for PCL and PEG crystal identification, respectively.

crystallization is strongly affected by the PCL content. In fact, PEGCL-I-50 exhibits a peak around 0-3 ${ }^{\circ} \mathrm{C}$ and with a crystallization enthalpy comparable to the first peak, while PEGCL-I-25_1 exhibits a peak around $-31^{\circ} \mathrm{C}$, with a very small enthalpy. PEGCL-II-25, having PEG3400, exhibits a peak around $-8{ }^{\circ} \mathrm{C}$, with a higher enthalpy value than that detected for PEGCL-I-25_1. Finally, PEGCL-I-25_2, having higher MW, exhibits a single exothermic peak at $1.6^{\circ} \mathrm{C}$, indicating a strong hindrance to the crystallization process (Table 2 ).

During the second heating scan, PEGCL-I-50 exhibits two fairly sharp melting peaks, the first at $35-36{ }^{\circ} \mathrm{C}$ and the second at $47-48{ }^{\circ} \mathrm{C}$. PEGCL-I-25_1 exhibits a small exothermal peak at about $-35{ }^{\circ} \mathrm{C}$ after the $\mathrm{Tg}$, attributed to the cold crystallization of PEG segments that achieve more freedom after the glass transition and are capable to arrange in a small crystalline domain [19, 20].

PEGCL-I-25_ 1 also exhibits a small melting peak at $18-22{ }^{\circ} \mathrm{C}$ and a second one at $45-47{ }^{\circ} \mathrm{C}$. The first peak is broader and was attributed to the PEG component, which is in lower amount and whose crystallization is strongly hampered by the PCL segments, while the second peak with sharper shape was attributed to the melting of PCL crystalline domains. This is confirmed by the fact that the single melting peak of PCL-HMDI appears at $46.4^{\circ} \mathrm{C}$. Also PEGCL-II-25 exhibits two melting points, the first one broad, at about $40{ }^{\circ} \mathrm{C}$, and the second one sharp, at about $46{ }^{\circ} \mathrm{C}$. PEGCL-I-25_2, having a very high molecular weight, exhibits a single melting peak around $42{ }^{\circ} \mathrm{C}$ (Table 3 ).

Few conclusions can be drawn, which are further confirmed by WAXD measurements. In particular, WAXD has been used to qualitatively evaluate crystallinity of the copolymers, since the crystalline structure of PEG and PCL domains exhibit characteristic diffraction patterns.

In Fig. 3, PCL-HMDI, PEGCL-I-50, PEGCL-I-25_1 and 2 WAXD diffraction spectra are reported, in comparison with PCL2000 and PEG2000 macrodiols used for their synthesis.

In particular, WAXD patterns of PCL macrodiol show an intense peak at $2 \theta=21.7^{\circ}$ and a smaller one at $23.8^{\circ}$, whereas PEG macrodiol shows two almost equally intense peaks at $2 \theta=19.4^{\circ}$ and $23.7^{\circ}$. Therefore we used peaks at $21.7^{\circ}$ and $19.4^{\circ}$ for PCL and PEG crystals identification, respectively.

The crystalline structure of PCL-HMDI almost corresponds to that of PCL macrodiol. In PEGCL-I-50 WAXD patterns, both PCL and PEG diffraction peaks are detected. In PEGCL-I-25_1, an obviously intense PCL crystal diffraction peak and a quite weak one for $\mathrm{PEG}$ crystal are observed, while no diffraction peaks typical of crystalline PEG appear in the spectrum of PEGCL-I-25_2, showing that PEG blocks resulted enable to crystallize. This finding, in good agreement with DSC results, can be assigned to the high molecular weight of PEGCL-I-25 2 . In general, it seems that the two components of the multiblock copolymers have the ability to segregate in domains and crystallize separately, but when the molecular weight is very high as for PEGCL-I-25_2, this process is somehow hampered, as confirmed by the previously reported surface investigation of these copolymer films [17] and a single large melting peak is observed.

The presence of the two components mutually affects the crystallization and melting temperatures. In particular, PCL domains crystallize first and interfere with PEG 


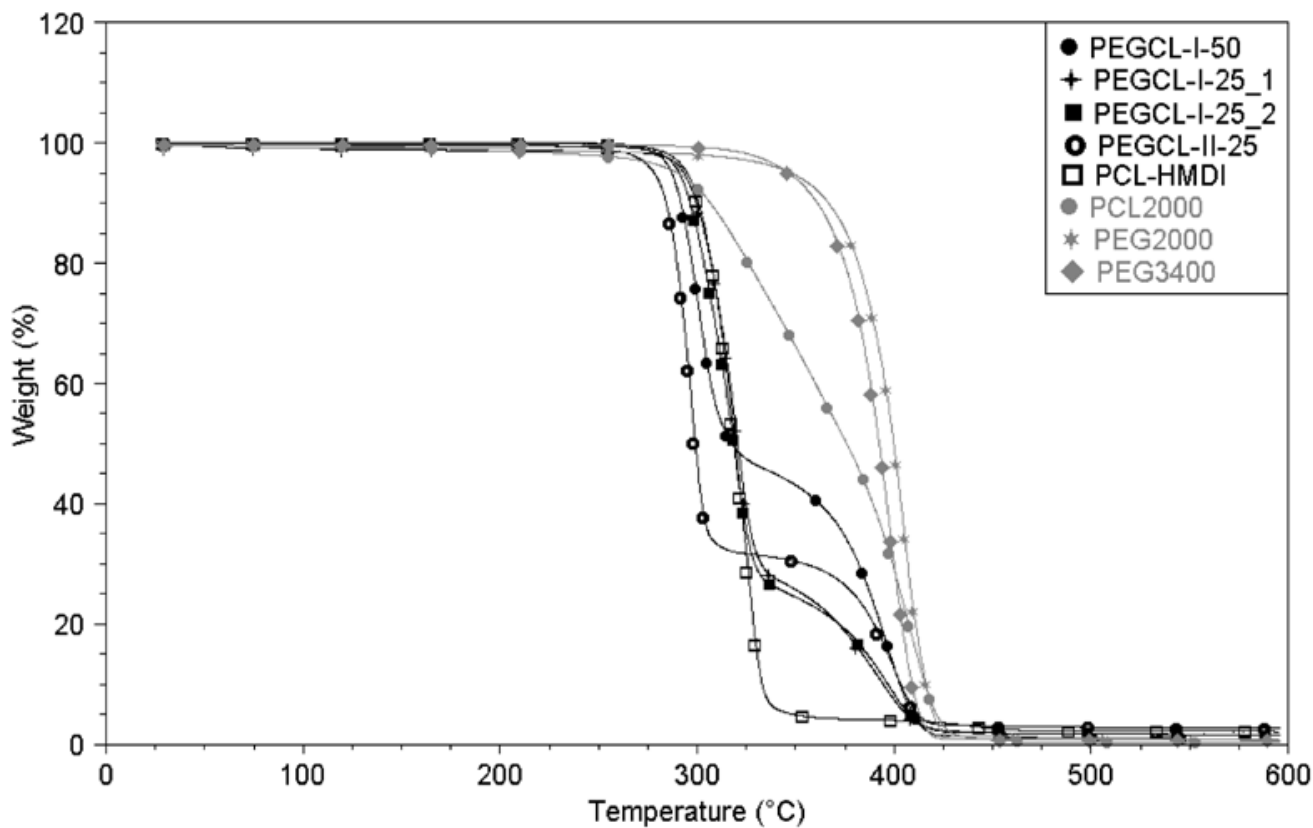

Fig. 4 TGA thermograms of PEGCL copolymers and their precursors (Heating rate: $10{ }^{\circ} \mathrm{C} / \mathrm{min}$ to $600{ }^{\circ} \mathrm{C}$ under $\mathrm{N}_{2}$ ).

crystallization, whose exothermal peak is shifted to lower temperature and has a broader shape. Also all the melting peaks are shifted to lower temperatures than the pristine oligomers. This behaviour has been previously reported for PEG/PCL copolymers [21].

The large undercooling, calculated as $\Delta \mathrm{T}=\mathrm{T}_{\mathrm{m}}-\mathrm{T}_{\mathrm{c}}$, which was observed for most of the melting/crystallization transitions, confirms the mutual interference in the crystallization process, which requires lower temperatures to be accomplished. For the examined copolymers, $\Delta \mathrm{T}$ values are in the range of $35-52{ }^{\circ} \mathrm{C}$ for the transition of PEG domain and $30-40{ }^{\circ} \mathrm{C}$ for that of PCL domain.

Previous studies on the thermal behaviour of PEGPCL block copolymers agree that if PCL segment is long enough, its crystallization occurs first during the cooling from the melt, fixing the whole structure of the spherulites and leading to a significant undercooling and imperfect crystallization of the PEG block [22].

When PCL segments are shorter, there is a significant mutual influence of the two components, which leads to imperfect spherulites morphology [23]. The interaction of the two components also affects the crystallinity of the two domains, which can be calculated from the fusion enthalpy of the relevant melting peak, normalized to its actual content, supposing that there is no contribution from the other component. For instance, to calculate the percentage of crystallinity of the PCL domain, the $\Delta \mathrm{H}_{\mathrm{m}}$ of the relevant peak is normalized to the weight content of PCL in the copolymer and rationed to the $\Delta \mathrm{H}_{\mathrm{m}}$ of a $100 \%$ crystalline PCL $\left(\Delta \mathrm{H}_{\mathrm{m}}=139.5 \mathrm{~J} \mathrm{~g}^{-1}\right)$ [24]. Crystalline percentage for PCL-HMDI and for PEGCL-I-25_1, PEGCL-I-25 2 and PEGCL-II-25 copolymers ranges between 43 and $47 \%$, while for PEGCL-I-50 is between $30-35 \%$.
Table 4. TGA results of PEGCL copolymers and their acromonomers.

\begin{tabular}{|c|c|c|c|c|}
\hline Run & $\begin{array}{c}\mathbf{T}_{\text {onset }}{ }^{\mathbf{a}} \\
\left({ }^{\circ} \mathbf{C}\right)\end{array}$ & $\begin{array}{c}\mathbf{T}_{\text {1max }} \\
\left({ }^{\circ} \mathbf{C}\right)\end{array}$ & $\begin{array}{c}\mathbf{T}_{\text {2max }} \\
\left({ }^{\circ} \mathbf{C}\right)\end{array}$ & Residue $^{\mathbf{b}}$ \\
\hline PEG2000 & 301.8 & $/$ & 405.4 & 0.89 \\
\hline PEG3400 & 327.2 & $/$ & 397.9 & 0.84 \\
\hline PCL2000 & 244.2 & 333.1 & 406.9 & 0.36 \\
\hline PCL-HMDI & 286.1 & 323.7 & $/$ & 2.13 \\
\hline PEGCL-I-50 & 280.4 & 300.4 & 396.2 & 1.09 \\
\hline PEGCL-I-25_1 & 280.2 & 319.4 & 393.2 & 1.63 \\
\hline PEGCL-I-25_2 & 282.4 & 307.2 & 395.5 & 1.62 \\
\hline PEGCL-II-25 & 266.9 & 303.6 & 378.4 & 2.7 \\
\hline
\end{tabular}

a: $\mathrm{T}$ onset was calculated at weight loss $\%=2 \%$;

b: Residue was calculated at $580^{\circ} \mathrm{C}$.

\section{Thermal Gravimetric Analysis}

Thermal stability of the copolymers was evaluated by thermal gravimetric analysis at $10{ }^{\circ} \mathrm{C} \mathrm{min}-1$ heating rate under non-oxidative conditions (Fig. 4 and Table 4).

The $\mathrm{T}_{\text {onset }}$ of the degradation was defined as the temperature at which $2 \%$ of weight loss was measured and the decomposition temperature $\left(\mathrm{T}_{\mathrm{d}}\right)$ as the temperature at which the maximum decomposition rate was measured during a degradation step. The pristine PEG2000 exhibits a $\mathrm{T}_{\text {onset }}$ at $301.8{ }^{\circ} \mathrm{C}$ and a single decomposition step at $405.4{ }^{\circ} \mathrm{C}$, while PEG3400 a T ${ }_{\text {onset }}$ at $327.2{ }^{\circ} \mathrm{C}$ and a single decomposition step at $397.9^{\circ} \mathrm{C}$. PCL2000 exhibits a 
http://nanobe.org

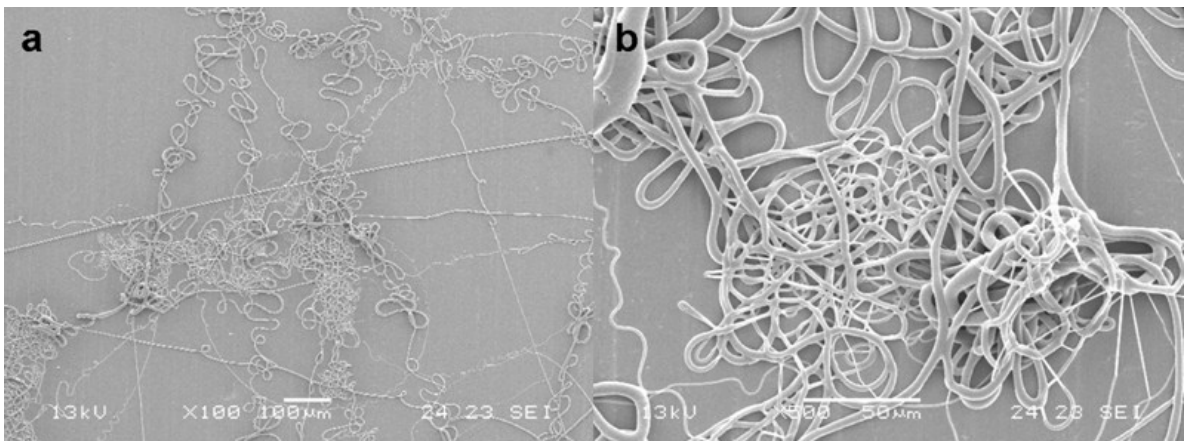

Fig. 5 SEM micrographs of electrospun PEGCL-I-25_2 (d=30 cm, V=30 KVolt) with $100 \mu \mathrm{m}$ (a) and 50 $\mu \mathrm{m}$ (b) scale bar

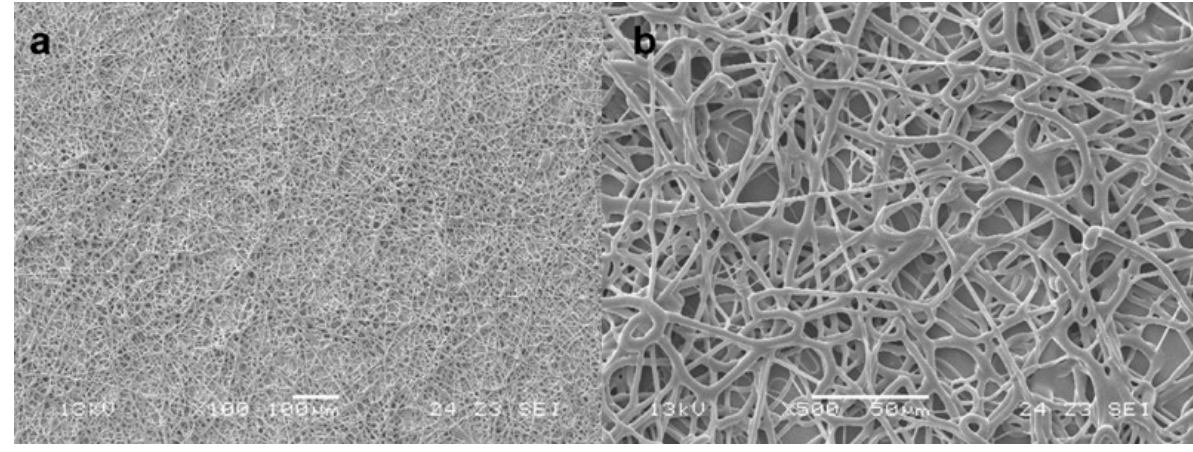

Fig. 6 SEM micrographs of electrospun PEGCL-I-25_2 (d=30 cm, V=46 KVolt) with $100 \mu \mathrm{m}$ (a) and $50 \mu \mathrm{m}$ (b) scale bar.

$\mathrm{T}_{\text {onset }}$ at $244.2^{\circ} \mathrm{C}$ and two decomposition steps at $333.1^{\circ} \mathrm{C}$ and $406.9^{\circ} \mathrm{C}$, respectively, which give some credit for a thermal degradation involving two consecutive mechanisms [25]. For all the investigated oligomers the residue at $580{ }^{\circ} \mathrm{C}$ was below $1 \%$.

The homopolymer PCL-HMDI showed only one decomposition step. This is partly due to the higher molecular weight of the copolymers and partly due to the absence of low molecular weight oligomer/polymer chains present in the PCL-HMDI homopolymer sample. It should be noted that the GPC analysis of the copolymers gave a broader molecular weight distribution with high polydispersity indexes, while PCL-HMDI had narrower PDI $=1.7$ (see Table 1$)$. All the copolymers containing PEG2000 exhibit a similar $\mathrm{T}_{\text {onset }}$ around $280{ }^{\circ} \mathrm{C}$, an intermediate value between those of the two components, and two decomposition steps, as depicted in Table 4.

The first one at $300-320{ }^{\circ} \mathrm{C}$ with a weight loss $\left(\Delta \mathrm{w}_{1}\right)$ is approximately in agreement with the PCL content and the second one around $396{ }^{\circ} \mathrm{C}$ is relevant to the $\mathrm{PEG}$ component as confirmed also by the weight loss $\left(\Delta \mathrm{w}_{2}\right)$. For all the investigated copolymers the residue at $580^{\circ} \mathrm{C}$ was below 3\%. The copolymer containing PEG3400 exhibits a $\mathrm{T}_{\text {onset }}$ around $267{ }^{\circ} \mathrm{C}$ and complete degradation occurs at about $378^{\circ} \mathrm{C}$, a value lower than its precursors.

\section{Electrospinning}

For tissue engineering applications, a polymeric material needs to be easily processed into a highly porous scaffold with a high surface area to volume ratio and an interconnected pore network [26]. PCL/PEG-based copolymers or blends are usually electrospinned by meltelectrospinning [27, 28].

In this work, the copolymer PEGCL-I-25_2 copolymer was processed by using a standard solution electrospinning technique and was preferred among the other copolymers in virtue of its higher molecular weight. High molecular weight polymers enable a better entanglement of the macromolecular chains in solution during electrospinning which is necessary for fibers formation [29].

A solution of PEGCL-I-25_2 in chloroform (10\% w/ v) was electrospun at a spinning voltage at $30 \mathrm{KVolt}$ and $30 \mathrm{~cm}$ distance needle to collector. In the electrospinning process, polymeric jets undergo an electrostatic instability deriving from mutual repulsion of charges that leads to the rapid rotation of the polymeric jet in the whipping process, with the formation of an untidy conical fibrous mesh [30].

The electrospinning process of the prepared PEGCL-I-25_2 solution did not exhibit the previously mentioned phenomena and resulted in the deposition on the collector of a single fibre which followed a random pattern (Fig. 5).

This phenomenon is quite common in the electrostatic drawing of non-conductive fluids [31]. What is used in these cases is a mixture of solvents (e.g. chloroform/ DMF) one having a higher dielectric constant to increase the solution conductivity. This has already been 
proved to be a good expedient to improve morphology and diameters of fibers during electrospinning of low conductivity polymer solutions [32].

However, in our case it was sufficient to vary the applied potential to obtain a jet with a significant stronger whipping motion that resulted in entangled fibers with reduced diameters. When the potential was increased from 30 to $46 \mathrm{KVolt}$ (while keeping the distance $30 \mathrm{~cm}$ ) homogenous electrospun fibers mats were obtained. Fibers appeared curly and flexible, with diameters in the range 1-3 $\mu \mathrm{m}$ and only very few sub-micron fibers were present (Fig. 6).

This preliminary results show than these polyurethanes could be of particular interest for TE applications due to their ability to be processed by electrospinning technology. Work is in progress in order to evaluate the processability by electrospinning of the other copolymers reported in Table 1, i.e. having lower molecular weight, different PCL/PEG ratio or different PEG segment's length and finally to evaluate the influence of these characteristics on their biological response.

\section{Conclusions}

Random multiblock amphiphilic PEEUs containing PEG and PCL segments were prepared by an optimised one-step and solvent-free synthetic route with high yields. The prepared copolymers displayed phase segregation of the two components, which mutually affect the thermal properties of the material.

\section{Acknowledgements}

The work was performed within the framework of FIRB-2005 - prot. RBIN043BCP, PRIN-2006- prot. 2006038548 projects and within the general scope NoE Expertissues CT -2004 -500328. The authors wish to thank Mr. Narducci for the SEM images.

\section{References}

1. Storck M, Orend KH, Schmitzrixen T. Absorbable suture in vascular surgery. Vascular Surgery. 1993; 27: 413-424. Doi: $10.1177 / 153857449302700601$.

2. Ferreira P, Silva AFM, Pinto MI, Gil MH. Development of a biodegradable bioadhesive containing urethane groups. Journal of Material Science - Materials in Medicine. 2008; 19(1): 111-120. Doi: 10.1007/s10856-007-3117-3.

3. Jeong B, Bae YH, Lee DS, Kim SW. Biodegradable block copolymers as injectable drug-delivery systems. Nature. 1997; 388(6645): 860-862. doi: 10.1038/42218.

4. Amsden BG. Biodegradable elastomers in drug delivery. Expert Opinion in Drug Delivery. 2008; 5:175-187. Doi:10.1517/17425247.5.2.175

5. Cohn D, Elchai Z, Gershon B, Karck M, Lazarovici G, Sela J, Chandra M, Marom G, Uretzky G. Introducing a selectively biodegradable filament wound arterial prosthesis: A shortterm implantation study. Journal of Biomedical Materials Research. 1992; 26: 1185-1205. Doi: 10.1002/jbm.820260909.

6. Cohn D, Stern T, Gonzalez MF, Epstein J. Biodegradable poly(ethylene oxide)/poly( $\varepsilon$-caprolactone) multiblock copolymers. Journal of Biomedical Materials Research. 2002; 59: 273-281. Doi: 10.1002/jbm. 1242.

7. Fernandez M, Jimenez J, Marcos-Fernandez A, Lopez-Bravo A, Roman JS. Biodegradable poly(ester-urethane-urea)s based with amino acids for tissue engineering and drug release. Tissue Engineering Part A. 2008; 14(5):704. Doi: 10.1089/tea.2008.1504.

8. Guelcher SA. Biodegradable polyurethanes: Synthesis and applications in regenerative medicine. Tissue Engineering Part B-Reviews. 2008; 14(1):3-17. Doi:10.1089/teb.2007.0133.

9. Li SM, Espartero JL, Foch P, Vert M. Structural characterization and hydrolytic degradation of a $\mathrm{Zn}$ metal initiated copolymer of L-lactide and $\varepsilon$-caprolactone. Journal of Biomaterials Science-Polymer Edition. 1996; 8(3):165-187. Doi: 10.1163/156856296X00237.

10. Han DK, Park KD, Hubbel JA, Kim YH. Surface characteristics and biocompatibility of lactide-based poly(ethylene glycol) scaffolds for tissue engineering. Journal of Biomaterials Science-Polymer Edition. 1998; 9(7): 667-680. Doi: 10.1163/156856298X00082.

11. Huang MH, Li SM, Hutmacher DW, Schantz JT, Vacanti CA, Braud C, Vert M. Degradation and cell culture studies on block copolymers prepared by ring opening polymerization of $\varepsilon$-caprolactone in the presence of poly(ethylene glycol). Journal of Biomedical Materials Research Part A. 2004; 69A(3):417-427. Doi: 10.1002/jbm.a.30008.

12. Yen MS, Kuo SC. PCL-PEC-PCL triblock copolydiol-based waterborne polyurethane .1 . Effects of the soft-segment composition on the structure and physical properties. Journal of Applied Polymer Science. 1997; 65(5):883-892. Doi: 10.1002/(SICI)10974628(19970801)65:5<883::AID-APP5>3.0.CO;2-J.

13.Gorna K, Gogolewski S. In vitro degradation of novel medical biodegradable aliphatic polyurethanes based on $\varepsilon$-caprolactone and Pluronics with various hydrophilicities. Polymer Degradation and Stability. 2002; 75(1):113-122. Doi:10.1016/S0141-3910(01)002105.

14.Yeganeh H, Jamshidi H, Jamshidi S. Synthesis and properties of novel biodegradable poly(epsilon-caprolactone)/poly(ethylene glycol)-based polyurethane elastomers. Polymer International. 2007; 56(1):41-49. Doi: 10.1002/pi.2107.

15. Lee JW, Hua F, Lee DS. Thermoreversible gelation of biodegradable poly( $\varepsilon$-caprolactone) and poly(ethylene glycol) multiblock copolymers in aqueous solutions. Journal of Controlled Release, 2001; 73(2-3):315-327. Doi:10.1016/S0168-3659(01)00297-8.

16. Cometa S, Bartolozzi I, Corti A, Chiellini F, De Giglio E, Chiellini E. Hydrolytic and microbial degradation of multi-block polyurethanes based on poly( $\varepsilon$-caprolactone)/poly(ethylene glycol) segments. Polymer Degradation and Stability. 2010; 95: 2013-2021. Doi:10.1016/j.polymdegradstab.2010.07.007.

17.Cometa S, Chiellini F, Bartolozzi I, Chiellini E, De Giglio E, Sabbatini L. Surface Segregation Assessment in Poly( $\varepsilon$ caprolactone)-poly(ethylene glycol) Multiblock Copolymer Films. Macromolecular Bioscience. 2010; 10(3):317-327. Doi: 10.1002/ mabi.200900284.

18.Gan ZH, Zhang J, Jiang B. Poly( $\varepsilon$-caprolactone)/poly(ethylene oxide) diblock copolymer II. Nonisothermal crystallization and melting behavior. Journal of Applied Polymer Science. 1997; 63(13): 1793-1804. DOI: $10.1002 /(\mathrm{SICI}) 1097$ 4628(19970328)63:13<1793::AID-APP12>3.0.CO;2-\#.

19. Wellen RMR, Rabello MS. The kinetics of isothermal cold crystallization and tensile properties of poly(ethylene terephthalate). Journal of Materials Science. 2005; 40(23):6099-6104. DOI: 10.1007/s10853-005-3173-3.

20.Hatakeyma T, Kasuga H, Tanaka M, Hatakeyama H. Cold crystallization of poly(ethylene glycol)-water systems. Thermochimica Acta. 2007; 465(1-2):59-66. Doi:10.1016/ j.tca.2007.09.005.

21.Bogdanov B., Vidts A., Van Den Bulcke A., Verbeeck R. and Schacht E. (1998) Synthesis and thermal properties of poly(ethylene glycol)-poly( $\varepsilon$-caprolactone) copolymers. Polymer. 39(8-9):16311636. Doi:10.1016/S0032-3861(97)00444-8.

22.Bogdanov B, Vidts A, Schacht E, Berghmans H. Isothermal crystallization of poly( $\varepsilon$-caprolactone-ethylene glycol) block copolymers. Macromolecules. 1999; 32(3): 726-731. Doi: 10.1021/ ma980226a.

23. Zhu WP, Xie WH, Tong XW, Shen ZQ. Amphiphilic biodegradable poly(CL-b-PEG-b-CL) triblock copolymers prepared by novel rare earth complex: Synthesis and crystallization properties. European Polymer Journal. 2007; 43:3522-3530. Doi:10.1016/j.eurp olymj.2007.04.024.

24.Khambatta FB, Warner F, Russel T, Stein RS. Small-angle X-ray 
and Klee D. (2008) Biofunctionalized poly(ethylene glycol)-blockand light scattering studies of morphology of blends of poly $(\varepsilon-$ caprolactone) with polyvinyl-chloride. Journal of Polymer Science B - Polymer Physics Edition. 1976; 14(8):1391-1424. Doi: 10.1002/ pol.1976.180140805.

25 Persenaire O, Alexandre M, Degée P, Dubois P. Mechanisms and Kinetics of Thermal Degradation of Poly( $\varepsilon$-caprolactone). Biomacromolecules. 2001; 2(1):288-294. Doi: 10.1021/bm0056310.

26.Cicotte KN, Hedberg-Dirk EL, Dirk SM. Synthesis and electrospun fiber mats of low $\mathrm{Tg}$ poly(propylene fumerate-co-propylene maleate). Journal of Applied Polymer Science. 2010;117(4): 19841991. Doi: 10.1002/app.32014.

27.Dalton PD, Lleixa Calvet J, Mourran A, Klee D, Möller M. Melt electrospinning of poly(ethylene glycol-block-e-caprolactone). Biotechnology Journal. 2006; 1:998-1006. Doi:10.1002/ biot.200600064.

28.Dalton PD, Grafahrend D, Klinkhammer K, Klee D, Moeller M. Electrospinning of polymer melts: phenomenological observations. Polymer. 2005; 48: 6823-6833. Doi:10.1016/j.polymer.2007.09.037.

29.Grafahrend D, Lleixa Calvet J., Salber J., Dalton P.D., Moeller M. poly(epsilon-caprolactone) nanofibers for tissue engineering. Journal of Materials Science: Materials in Medicine, 19:1479-1484. Doi: 10.1007/s10856-007-3299-8.

30. Reneker DH, Yarin AL. Electrospinning jets and polymer nanofibers. Polymer. 2008; 49: 2387-2425. Doi:10.1016/j.polymer.2008.02.002.

31. Shin YM, Hohman MM, Brennerc MP, Rutledge GC. Experimental characterization of electrospinning: the electrically forced jet and instabilities. Polymer. 2001; 42(25): 9955-9967. Doi:10.1016/ S0032-3861(01)00540-7.

32. Ndreu A, Nikkola ANL, Ylikauppila H, Ashammakhi N, Hasirci V. Electrospun Biodegradable Nanofibrous Mats for Tissue engineering. Nanomedicine. 2008 3(1): 45-60. Doi:10.2217/17435889.3.1.45.

Copyright:(c) 2011 Irene Bartolozzi, et al. This is an open-access article distributed under the terms of the Creative Commons Attribution License, which permits unrestricted use, distribution, and reproduction in any medium, provided the original author and source are credited. 